\title{
POLYOVULAR FOLLICLES IN SQUIRREL MONKEYS AFTER PROLONGED DIETHYLSTILBOESTROL TREATMENT
}

\author{
C. E. GRAHAM AND CAROLYN F. BRADLEY \\ Yerkes Regional Primate Research Center, Emory University, \\ Atlanta, Georgia 30322, U.S.A.
}

(Received 12th November 1970)

\begin{abstract}
Summary. Almost $30 \%$ of ovarian follicles contained more than one oocyte in squirrel monkeys with chronic implants of diethylstilboestrol. Polyovular follicles were relatively infrequent in control animals. This finding raises the possibility of neogenesis of oocytes in adult haplorhine primates.
\end{abstract}

\section{INTRODUCTION}

Multiovular follicles have been observed in the ovaries of a number of species, including man, but their mode of origin has remained a matter for speculation (Brambell, 1956). Harrison (1948, 1949) noted increased frequencies of polyovular follicles during the late proliferative phase of the reproductive cycle in goats and squirrel monkeys, and speculated that this change might be related to oestrogen secretion. In the present communication, a marked increase in the incidence of polyovular follicles in squirrel monkeys treated with diethylstilboestrol is reported.

\section{MATERIALS AND METHODS}

Adult female squirrel monkeys, Saimiri sciureus (originating from dealers in Iquitos, Peru and Leticia, Colombia) of unknown age received subcutaneous $240-\mathrm{mg}$ implants of either pure pelleted diethylstilboestrol or cholesterol in the dorsal region. After varying lengths of treatment up to 14 months, the animals were killed and the ovaries and other genitalia were removed, fixed in Bouin's solution or buffered neutral formalin, and sectioned at $6 \mu \mathrm{m}$; representative paraffin wax-embedded sections were stained with haematoxylin and eosin, or periodic acid-Schiff with and without prior diastase digestion. The ovaries of a group of intact untreated animals were similarly prepared for microscopic examination.

\section{RESULTS}

The number of oocytes visible in each primordial follicle was counted in representative sections from each ovary (Table 1). In this study, a primordial follicle 


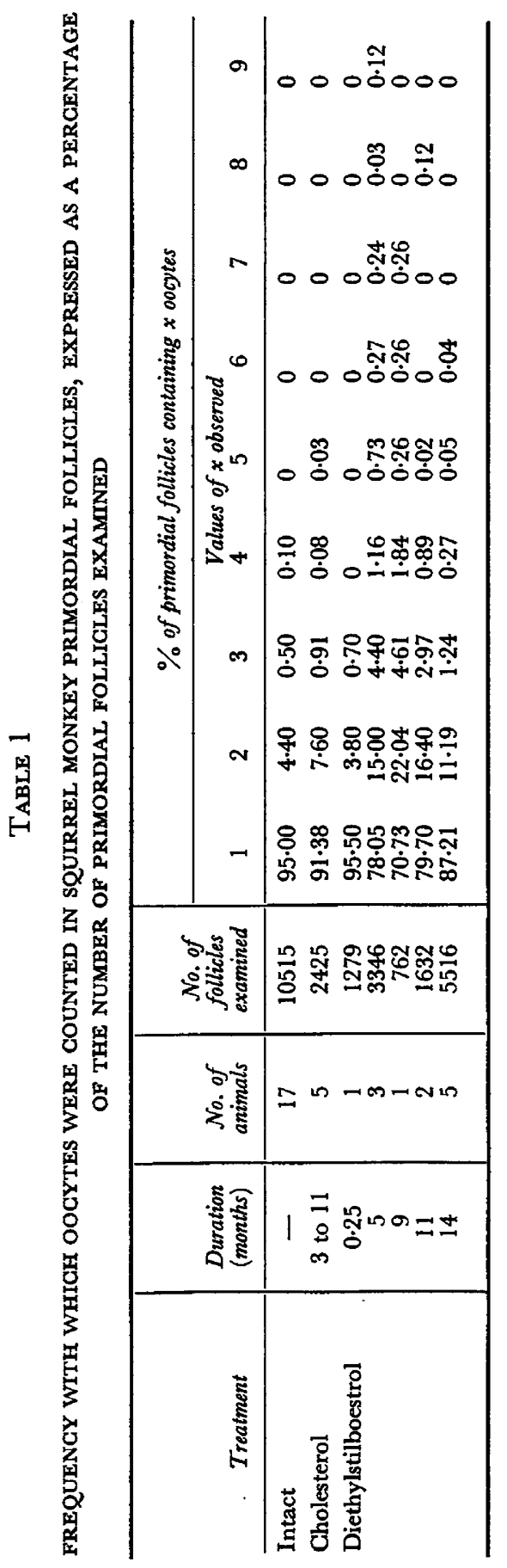






Polyovular follicles in the ovary of a squirrel monkey after treatment with dicthylstilboestrol for 5 months. Haematoxylin and cosin. $\times 200$. 
is defined as any follicle with no more than one layer of follicular epithelial cells. Thus, the relative frequency of primordial follicles containing different numbers of oocytes could be determined. (We preferred to determine relative frequencies rather than the absolute number of follicles of different sizes in each ovary, because Block (1951) has shown that absolute counts are impractical and inaccurate.)

In the intact animals, unclassified with respect to the stage of the reproductive cycle, $5.1 \%$ of the follicles were bi-, tri- or quadriovular. No larger numbers of oocytes were seen in the follicles of intact animals.

Unexpectedly, the cholesterol-treated control animals showed a somewhat higher incidence of polyovular primordial follicles than the intact animals; the significance of this finding is unknown. The diethylstilboestrol-treated animals showed polyovular primordial follicles (Plate 1), the incidence of which was greatly in excess of the control values, the highest value being almost $30 \%$ for the animal treated for 9 months (Table 1). Up to nine oocytes were counted in some follicles, but such counts obviously give a gross underestimate of the actual number of oocytes in each follicle, since only a small proportion of the oocytes contained in a large follicle would be transected in a single section.

The pellets were not obviously diminished in size after 14 months' treatment, but the diethylstilboestrol-treated animals nevertheless showed evidence of extreme oestrogenic stimulation throughout the entire period, including greatly enlarged labia and uterus, and a thickened, cornified, heavily desquamating vaginal mucosa. The cholesterol-treated animals showed no evidence of excessive oestrogenic response.

Although no extensive evidence of atresia was seen in the multiovular primordial follicles, a few of the oocytes in these follicles did show early atretic changes. A few growing follicles containing two or three ova were noted, and some of these ova were atretic.

\section{DISGUSSION}

Harrison (1949) recorded counts of $15 \%$ of bi- or triovular follicles in ovaries of four squirrel monkeys obtained during the follicular phase of the ovarian cycle, but lower counts (unspecified) during the luteal phase. The significance of his figures, which are considerably higher than those obtained in this study, is uncertain, as the conditions under which his counts were made, such as the thickness of the sections, are not given in detail.

Harrison (1949) further stated that evidence of atresia was present in most polyovular follicles in the primates he examined, and Hartman (1926) suggested that multiple follicle formation represents an atretic process; however, the lack of evidence of extensive atresia in the present study does not fully support this interpretation. The relationship of atresia to the formation of polyovular follicles might become clearer if animals were studied after withdrawal of the exogenous oestrogenic stimulus.

Only rarely were multinuclear ova found in the material examined. It is not generally considered that oogenesis occurs in the adult primate ovary, except in the prosimians such as Loris and Galago where oogenesis in the adult 
seems to be the normal situation (Anand Kumar, 1968; Butler, 1969; Butler \& Juma, 1970). In these prosimians, oogonia capable of mitotic proliferation into oocytes persist into adulthood; this proliferation of germ cells is favoured during the oestrogenic phase of the reproductive cycle, and aggregations comprising oogonia in various stages of mitosis, with oocytes in various stages of meiotic prophase, may be recognized. It is unknown whether or not these germ cells become part of the functional oocyte population capable of ovulation and fertilization.

The occurrence of numerous polyovular follicles in the diethylstilboestroltreated squirrel monkey suggests a type of proliferation similar to that described in prosimians. However, we could not identify any germ cells which might be considered capable of proliferation in ovaries from forty-four intact squirrel monkeys, i.e. no non-follicular oocytes or oogonia were present in the material examined. Only follicular oocytes could be found and their nuclei were indistinguishable from illustrations by Baker $(1963,1966)$ of arrested diplotene in man and the rhesus monkey. Since these cells have already entered meiosis, they are unlikely to be capable of mitosis. The nuclei of oocytes observed in polyovular follicles were similar to the nuclei of follicular oocytes in intact animals; that is, they also appeared to have entered meiosis, and thus they do not present the cytological characteristics of a proliferating population. The mode of origin of polyovular follicles in diethylstilboestrol-treated squirrel monkeys is thus unclear, and other possible ways in which polyovular follicles might arise must be considered. These include the aggregation of existing primary oocytes by migration, or loss of the follicular epithelium which normally separates groups of them. It may be concluded from the fact that no definite increase in the number or size of polyovular follicles occurred after 5 months (Table 1) that formation of polyovular follicles had come to an end by that time. Consequently, earlier stages of treatment will have to be studied in order to establish their mode of formation.

The findings recorded in this preliminary report are of considerable interest because they raise the possibility of oogenesis in adulthood in primates more advanced than the prosimians. They also appear to support Harrison's thesis that oestrogenic stimulation is accompanied by the formation of polyovular follicles in the intact primate. It is of special importance to determine whether this effect occurs in other primates including man, in view of the widespread therapeutic use of oestrogens and their inclusion in contraceptive regimens. Possible effects on fertility after withdrawal of a steroidal contraceptive must be considered.

\section{ACKNOWLEDGMENTS}

This research was supported by Public Health Service grants CA-10085 from the National Cancer Institute and RR-00165 from the National Institutes of Health. The authors wish to thank Mrs Carolyn Floyd for her technical assistance.

\section{REFERENGES}

Anand Kumar, T. C. (1968) Oogenesis in lorises; Loris tardigradus lydekkerianus and Nycticebus coucang. Proc. R. Soc. B, 169, 167. 
Baker, T. G. (1963) A quantitative and cytological study of germ cells in human ovaries. Proc. R. Soc. B, $158,417$.

BAKER, T. G. (1966) A quantitative and cytological study of oogenesis in the rhesus monkey. F. Anat., Lond. 100, 761.

BLock, E. (1951) Quantitative morphological investigations of the follicular system in women. Methods of quantitative determinations. Acta anat. 12, 267.

Brambell, F. W. R. (1956) Ovarian changes. In: Marshall's Physiology of Reproduction. Ed. A. S. Parkes. Longmans, London.

Butler, H. (1969) Post pubertal oogenesis in Prosimiae. Proc. 2nd int. Congr. Primat. 2, 15.

Butler, H. \& JumA, M. B. (1970) Oogenesis in an adult prosimian. Nature, Lond. 226, 552.

HARRISON, R. J. (1948) The changes occurring in the ovary of the goat during the estrous cycle and in early pregnancy. 7. Anat., Lond. 82, 21.

Harrison, R. J. (1949) Multiovular follicles in the ovaries of lower primates. Nature, Lond. $164,409$.

Hartman, C. J. (1926) Polynuclear ova and polyovular follicles in the opossum and other mammals, with special reference to the problem of fecundity. Am. F. Anat. 37, 1 . 